\title{
Aplikasi Pemesanan Makanan pada Restoran 1953 Indonesia Berbasis Web
}

\author{
Farida Nurlaila
}

\author{
Fakultas Teknik, Teknik Informatika, Universitas Pamulang, Pamulang, Indonesia \\ e-mail: dosen00676@unpam.ac.id
}

\begin{abstract}
The restaurant business is one area that promises many benefits. But in some cases, not all restaurants can run their business smoothly. For example because of the lack of promotion of the types of food offered, the variety of menus presented for the customer service process is unsatisfactory. This research was directed to Restoran 1953 Indonesia, because the problems mentioned above were experienced by Restoran 1953 Indonesia. For this reason, a system is needed that can solve problems in the restaurant business today. That way, this application can facilitate customers in the ordering process and Restoran 1953 Indonesia in providing the best service.
\end{abstract}

Keywords: customer, Restoran 1953 Indonesia, application

\section{Pendahuluan}

Restoran adalah suatu layanan yang pengoperasiannya berupa penjualan makanan atau minuman kepada tamu-tamu dalam kelompok kecil dengan maksud untuk mendatangkan keuntungan (Ninemeier \& Hayes, 2006). Pada umumnya tamutamu datang langsung ke restoran, kemudian penyajian dilakukan secara langsung di restoran. Sekarang ini telah banyak kita temukan jenis-jenis restoran yang menawarkan berbagai konsep untuk menarik lebih banyak pelanggan.

Restoran 1953 Indonesia adalah salah satu restoran yang berlokasi di Kebayoran Jakarta Selatan. Restoran ini berdiri pada tanggal 20 April 2016. Nama restoran ini sendiri diambil dari bangunan yang berdiri sejak tahun 1953 pada masa penjajahan Belanda sebagai pesaing baru di dunia kuliner. Restoran 1953 Indonesia dituntut menjadi sebuah restoran yang memberikan pelayanan terbaik kepada pelanggan, baik dalam menyajikan makanan, minuman, atau pun tempat yang nyaman kepada pelanggan.

Saat ini, restoran terus berupaya untuk meningkatkan kualitas dengan memberikan pelayanan terbaiknya kepada para pelanggan serta peningkatan dalam hal perolehan pendapatan, salah satunya dalam hal pemanfaatan teknologi informasi untuk menunjang bisnis restoran. Hal yang mendorong upaya tersebut yaitu media promosi yang digunakan dengan penyebaran brosur atau memasang spanduk masih terbatas pada tempat dan tentunya belum dapat memaksimalkan jumlah pendapatan restoran, sehingga perlu dilakukan promosi secara digital. Selain itu, proses pemesanan yang dilakukan melalui sambungan telepon terkadang ada kesalahpahaman antara pelanggan dan karyawan restoran.

Berdasarkan permasalahan di atas, perlu dirancang sistem informasi pemesanan makanan yang dapat membantu restoran dalam melakukan promosi secara digital sehingga restoran 1953 Indonesia akan lebih dikenal masyarakat. Selain daripada itu, sistem diharapkan dapat meringankan tugas operator dan menyingkat waktu dalam hal pengolahan data menu dan data pemesanan.

\section{Metodologi Penelitian}

Beberapa tahapan dari metode penelitian yang dilakukan dirinci menjadi proses-proses sebagai berikut:

a. Observasi

Proses observasi dilakukan untuk melihat secara langsung prosedur kerja manajemen restoran.

b. Wawancara

Wawancara dilakukan untuk mengetahui permasalahan yang ada, wawancara tersebut dilakukan terhadap manager dan karyawan Restoran 1953 Indonesia.

c. Studi Pustaka

Untuk mencapai tujuan penelitian, maka perlu mempelajari buku, artikel maupun jurnal yang berkaitan dengan penelitian ini. 


\section{Model Pengembangan Sistem}

Model pengembangan sistem yang digunakan pada sistem ini adalah model waterfall (Pressman, 2015) yang digambarkan dan meliputi beberapa proses yaitu:

a. Komunikasi (Communication)

Komunikasi dengan user sangat diperlukan untuk menafsirkan dan mencapai tujuan yang hendak dicapai. Inisialisasi proyek merupakan hasil dari proses komunikasi. Prosesnya mulai dari mengkaji permasalahan yang sedang dihadapi, menghimpun data-data yang dibutuhkan, serta membantu menerjemahkan fungsi software.

b. Perencanaan (Planning)

Proses selanjutnya yaitu merencanakan penjadwalan kerja yang akan dilaksanakan, sumber daya yang diperlukan dalam membuat sistem, mengidentifikasi tugas-tugas apa saja yang akan dikerjakan, resiko yang mungkin terjadi, produk seperti apa yang ingin dihasilkan, dan monitoring proses pembuatan sistem.

c. Pemodelan (Modelling)

Tahapan selanjutnya permodelan sistem yang prosesnya menitikberatkan pada perancangan struktur data, algoritma, arsitektur software dan tampilan layar aplikasi. Tujuannya agar lebih memahami gambaran sistem yang akan dibuat.

d. Konstruksi (Construction)

Proses ini merupakan yaitu menerjemahkan bentuk pemodelan menjadi pengkodean dengan bahasa pemrograman yang dapat dikenali oleh mesin. Setelah membuat pengkodean, langkah selanjutnya dilakukan pengujian terhadap sistem. Tujuan dari proses ini yaitu menemukan dan memperbaiki kesalahan yang mungkin terjadi di kemudian hari.

e. Menyebarkan (Deployment)

Tahapan ini merupakan proses implementasi software ke user, mulai dari perawatan software yang dilakukan secara berkala, menilai kualitas software, penyempurnaan software, dan pengembangan software berdasarkan masukan-masukan yang diberikan agar sistem tetap dapat berjalan sesuai dengan fungsi yang diharapkan.

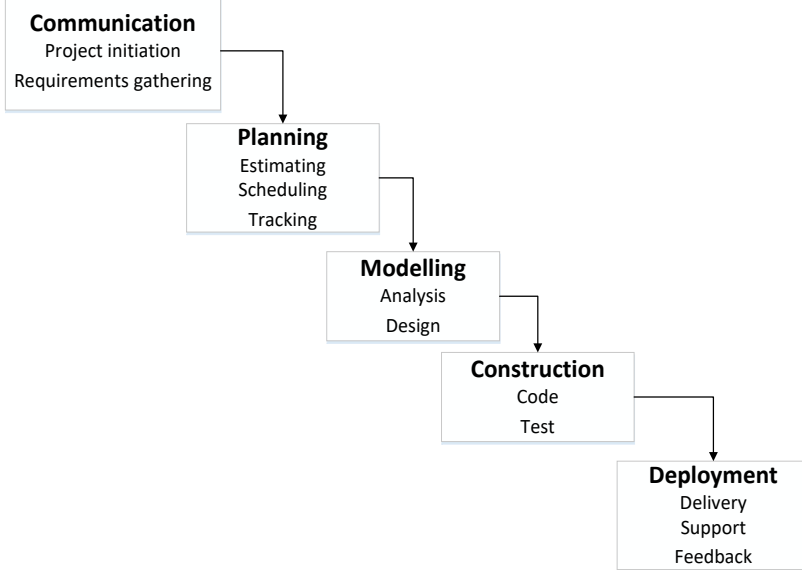

Gambar 1. Model Waterfall Pressman

\section{Web}

Web merupakan kumpulan laman yang saling terkait yang memuat informasi dalam bentuk teks, gambar, audio, animasi dan video atau gabungan dari semuanya, baik yang sifatnya dinamis maupun statis. Halaman - halaman web tersebut nantinya akan dihubungkan dengan hyperlink (Hariyanto, 2015).

\section{Hasil Dan Pembahasan}

Bagian ini akan menjelaskan mengenai langkah-langkah penyelesaian masalah pada Restoran 1953 Indonesia. Proses pertama dimulai dengan melakukan pengumpulan data melalui observasi dan wawancara dengan manager maupun karyawan restoran. Tahapan berikutnya, dengan mengidentifikasi masalah. Dari proses pengumpulan data didapati sejumlah masalah yaitu jumlah pelanggan yang datang belum signifikan. Umumnya pelanggan yang datang mengetahui keberadaan restoran ini dari brosur ataupun spanduk yang terpasang di sudut restoran. Untuk pemesanan tempat dan menu, restoran ini memfasilitasi pelanggan melalui sambungan telepon. Namun, terkadang pemesanan melalui sambungan telepon mengalami kesalahpahaman dalam hal menjelaskan spesifikasi tempat dan menu yang disediakan restoran dan yang diinginkan pelanggan.

Dari masalah di atas, perlu dilakukan perbaikan untuk meningkatkan pelayanan kepada pelanggan. Salah satunya dengan membuat sistem yang dapat mempermudah pelanggan melakukan pemesanan menu dan tempat, mempermudah 
restoran dalam mengelola menu makanan, jenis tempat dan pemesanan pelanggan.

Tahapan yang ketiga yaitu merancang sebuah sistem baru dalam bentuk skema database dan aturan sistem. Database (basis data) adalah kumpulan data yang didesain secara logis saling berhubungan dengan tujuan untuk mendapatkan data yang dibutuhkan oleh suatu organisasi
(Indrajani, 2015). Sementara aturan sistem digambarkan dengan use case diagram yang mendeskripsikan hubungan antara satu atau lebih aktor dengan aktifitas-aktifitas yang akan dilakukan aktor dalam sebuah sistem informasi (Rosa \& Shalahuddin, 2013). Kedua skema tersebut digambarkan pada Gambar 2 dan Gambar 3.

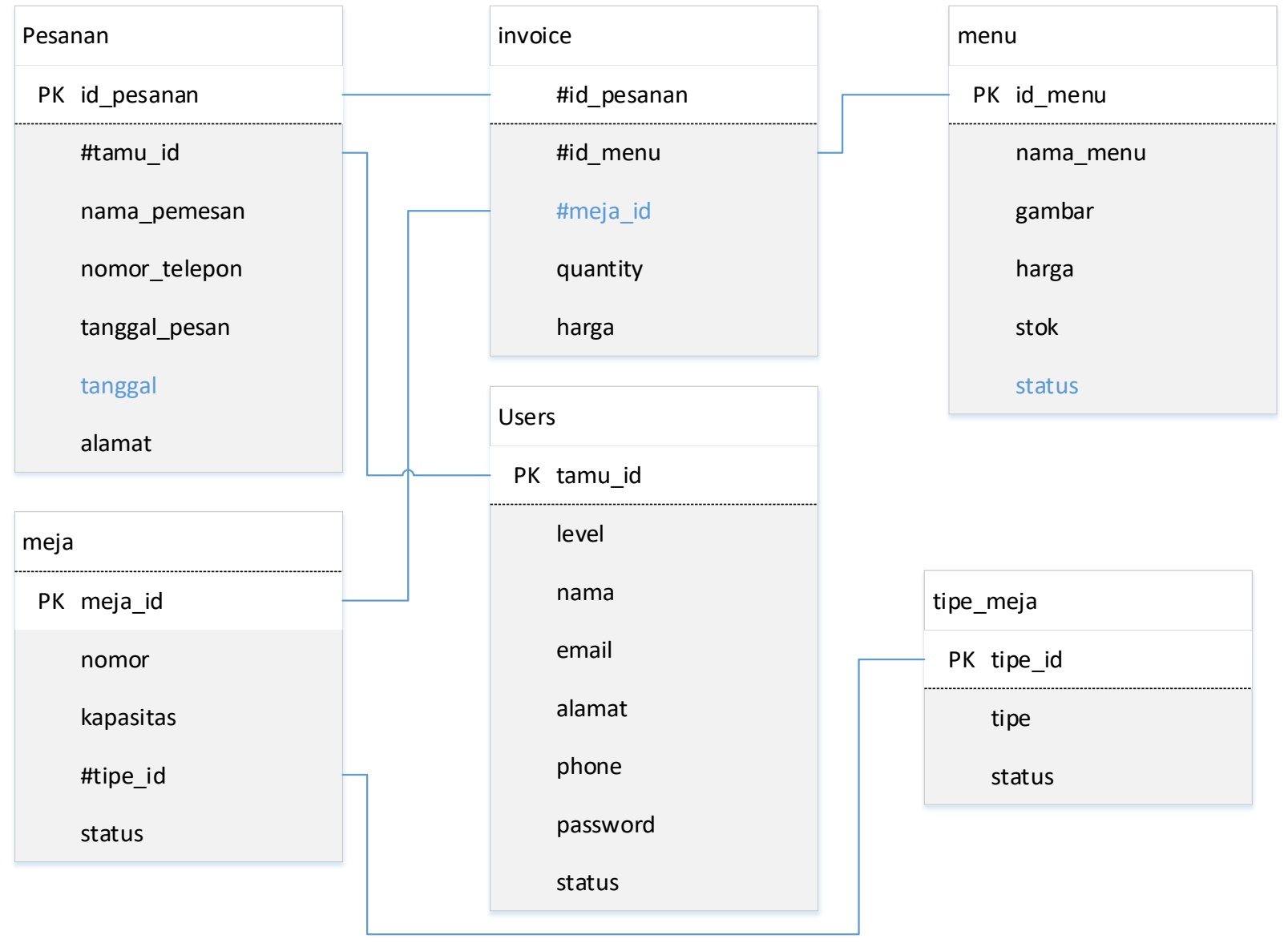

Gambar 2. Skema Database

Tahapan selanjutnya adalah pembuatan aplikasi. Acuan pembuatan berdasarkan skema yang telah dirancang pada skema database dan use case diagram. Aplikasi dibuat berbasis web, untuk mempermudah pelanggan melakukan pemesanan menu dan tempat yang diinginkan. Sehingga saat dihari kedatangan, pelanggan tidak perlu menunggu lama untuk menikmati hidangan restoran, karena sebelumnya telah melakukan pemesanan melalui aplikasi.

Setelah implementasi aplikasi, kemudian dilakukan pengujian aplikasi. Tujuannya untuk mengukur kualitas aplikasi dan memvalidasi apakah aplikasi telah sesuai dengan spesifikasi yang dibutuhkan. Berikut adalah tampilan aplikasi saat proses pengujian: 


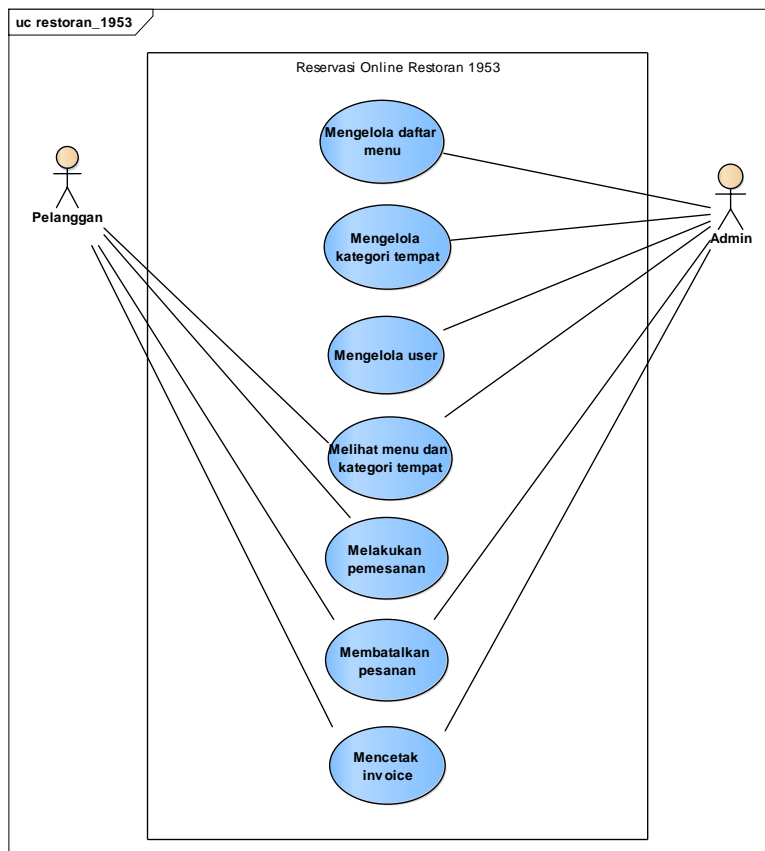

Gambar 3. Use Case Diagram

a. Halaman Kelola User

Pada halaman ini memungkinkan admin restoran dapat melakukan pengaturan pengguna aplikasi.

\begin{tabular}{l} 
Nama Lengkap \\
nida \\
Email \\
\hline nida@gmail.com \\
Phone \\
\hline 465247222 \\
Alamat \\
\hline Ranomeeto kendari \\
Level \\
Receptionist $\bigcirc$ Tamu $\bullet$ Admin \\
Status \\
on off \\
\hline update
\end{tabular}

\section{Gambar 4. Halaman Kelola User}

b. Halaman Kelola Kategori Tempat

Halaman ini memuat pegaturan untuk kategori tempat dengan masukan berupa nomor meja, kapasitas serta status.

\begin{tabular}{|c|}
\hline Nomor Meja \\
\hline VIP 1 \\
\hline Kapasitas \\
\hline 10 \\
\hline $\begin{array}{c}\text { Status } \\
- \text { on }\end{array}$ \\
\hline Update \\
\hline
\end{tabular}

Gambar 5. Halaman Kelola Kategori Tempat

c. Halaman Kelola Menu

Halaman ini memuat pengaturan untuk menu seperti penamaan menu, gambar menu, harga dan stok.

Nama Menu

Ayam Bakar Kecombrang

Gambar Menu (Klik pilih gambar jika ingin mengganti gambar disamping)

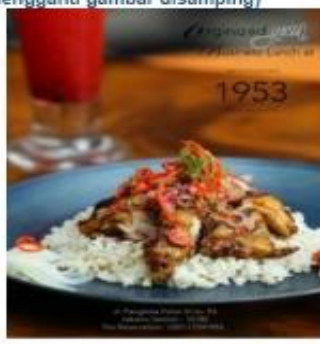

Harga

129000

Stok

25

undain

Gambar 6. Halaman Kelola Menu

d. Halaman Daftar Menu

Fitur yang tersedia pada menu ini yaitu memungkinkan pelanggan dapat melihat daftar menu yang tersaji pada Restoran 1953 Indonesia. 

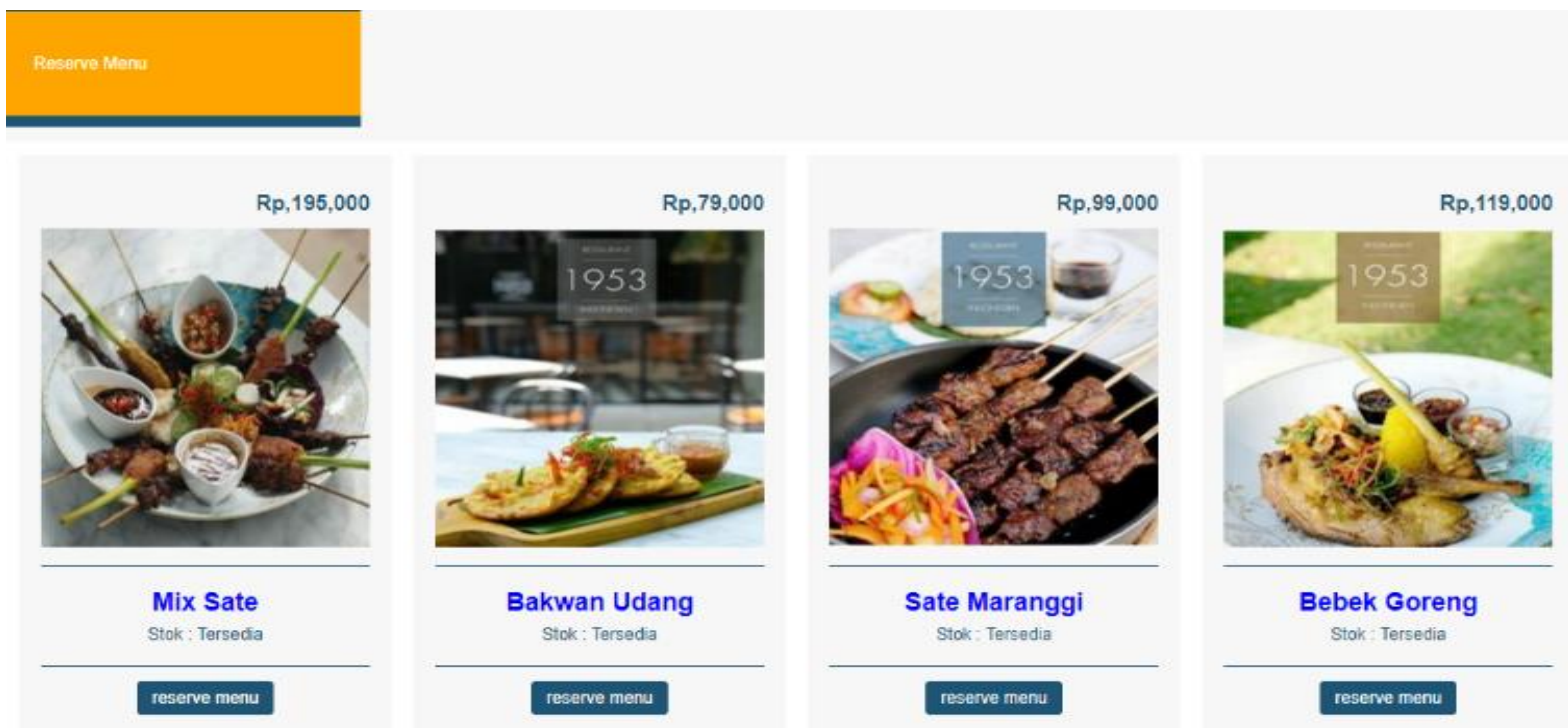

Gambar 7. Daftar Menu

Terdapat deskripsi menu berupa gambar, nama menu, harga, keterangan ketersediaan menu. Fitur lain yang disediakan yaitu proses pemesanan dapat dilakukan dengan memilih salah satu atau beberapa button reserve menu dari daftar makanan. b. Halaman Daftar Kategori Tempat

Fitur yang tersedia pada menu ini yaitu memungkinkan pelanggan dapat melihat daftar kategori tempat yang bisa dipilih. Fitur lain yang disediakan yaitu proses pemesanan dapat dilakukan dengan memilih salah satu button reserve dari daftar kategori tempat.

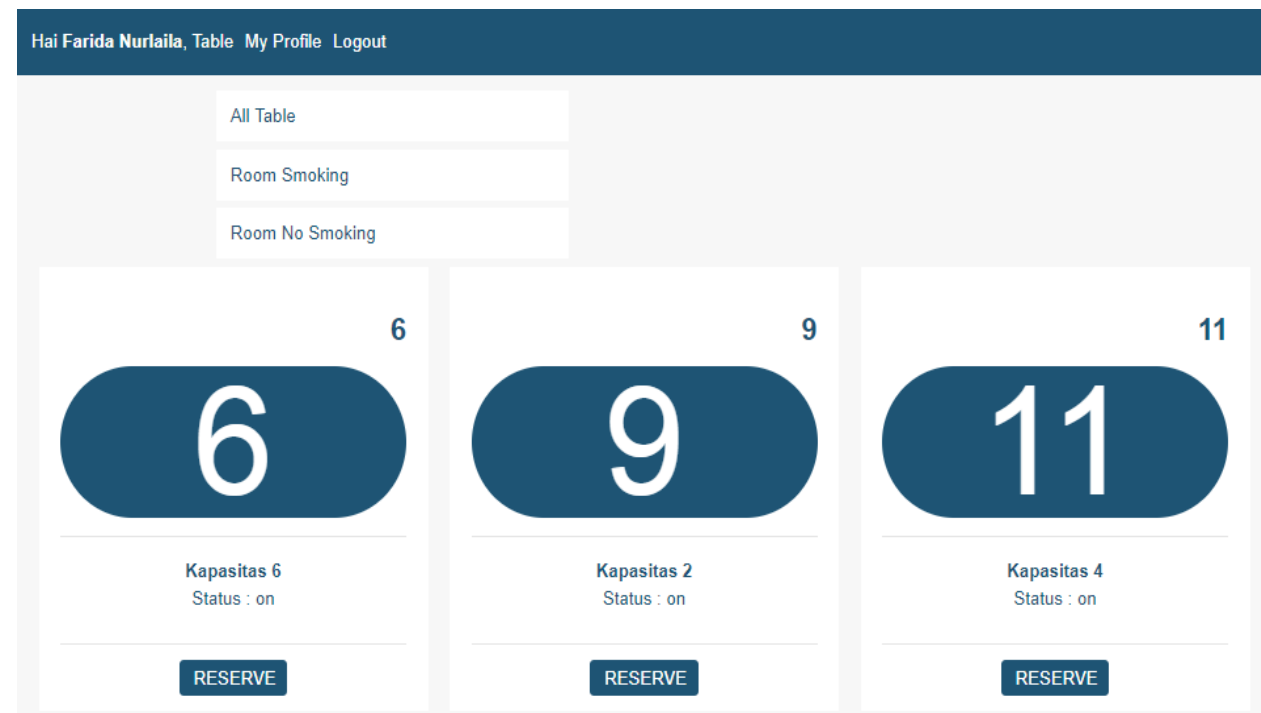

Gambar 8. Daftar Kategori Tempat

c. Halaman Detail Pesanan

Halaman ini berisi fitur untuk menampilkan detail pesanan berupa keterangan data pemesan, daftar makanan yang dipesan, kategori tempat yang dipesan dan total pembayaran. Selain itu pada halaman ini berisi fitur untuk memfasilitasi pembatalan pesanan dan fitur untuk cetak detail pesanan. 


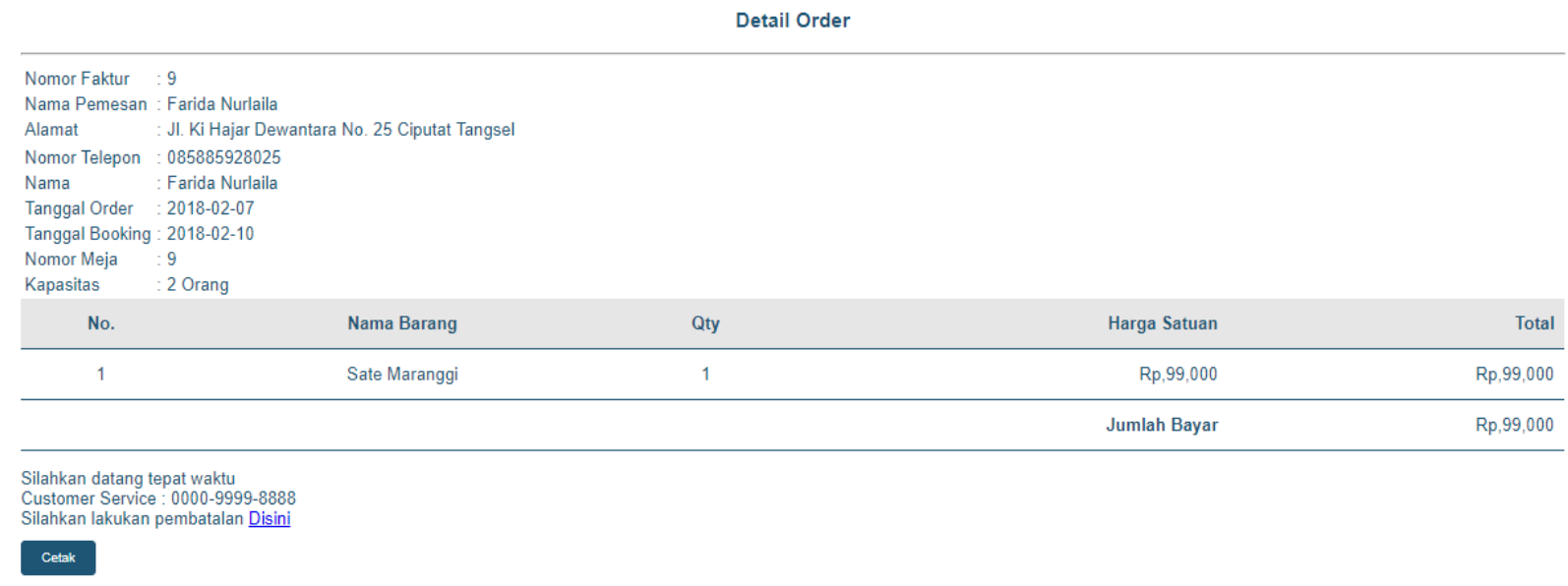

Gambar 9. Detail Pesanan

d. Halaman Cetak Detail Pesanan

Halaman ini memuat detail pesanan dalam bentuk cetak.

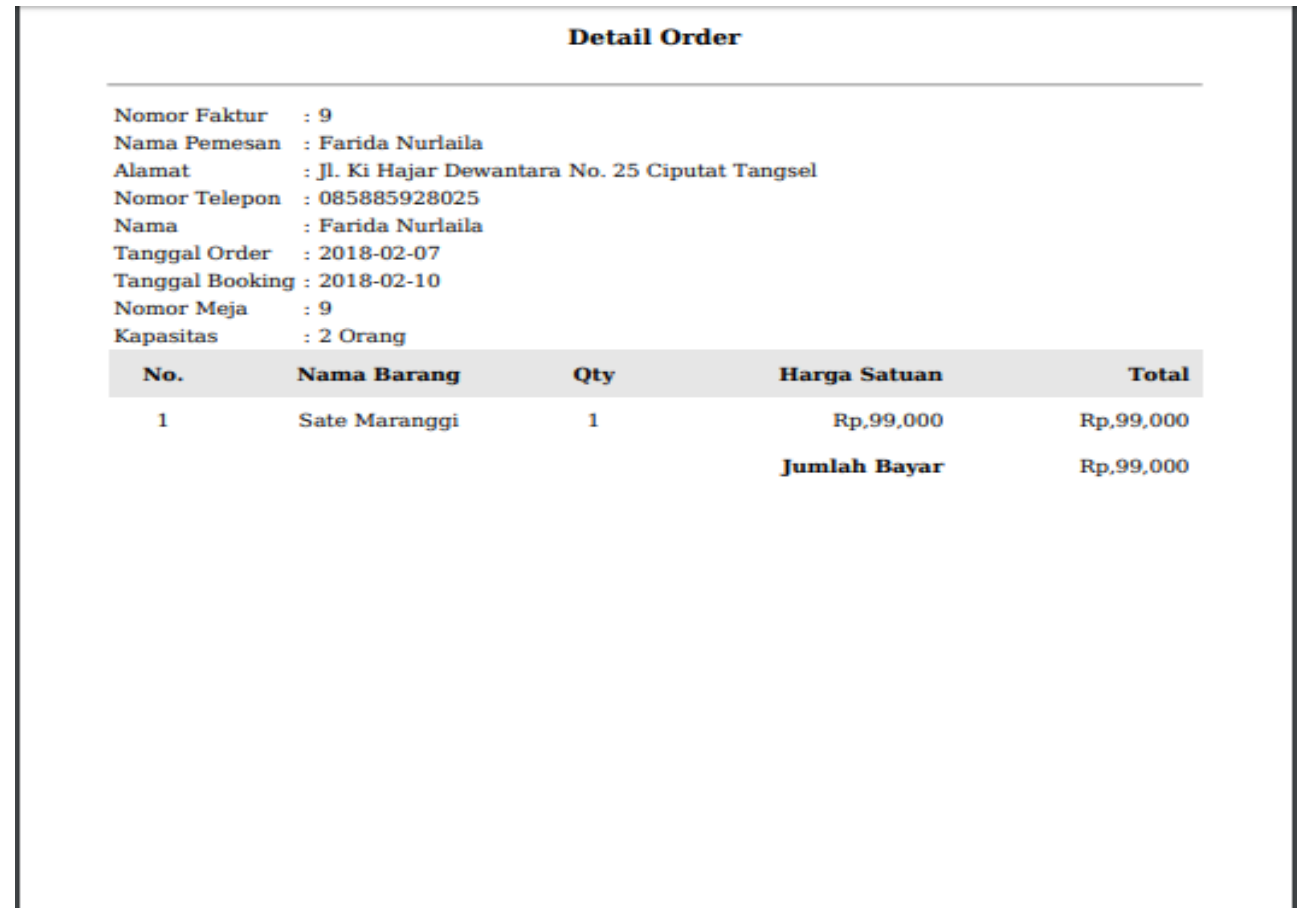

Gambar 10. Halaman Cetak Detail Pesanan

\section{Pengujian Software}

Pengujian merupakan bagian dari aktifitas dalam menjamin kualitas perangkat lunak yang bersifat kritis. Aktifitas ini sama halnya dengan analisis, desain dan pengkodean yang merupakan bagian dari pengembangan perangkat lunak (Shi, 2010).
Pengujian aplikasi ini menggunakan pendekatan black box testing. Black box testing dilakukan dengan merancang kasus uji yang berisi spesifikasi perangkat lunak (Nidhra \& Dondeti, 2012). Adapun hasil pengujiannya sebagai berikut: 
Tabel 11. Skema Pengujian

\begin{tabular}{|c|c|c|}
\hline $\begin{array}{c}\text { Skema } \\
\text { penguiian }\end{array}$ & $\begin{array}{c}\text { Hasil yang } \\
\text { diharapkan }\end{array}$ & Status \\
\hline $\begin{array}{l}\text { Admin } \\
\text { memasukkan } \\
\text { data menu }\end{array}$ & $\begin{array}{l}\text { Pada modul } \\
\text { admin muncul } \\
\text { halaman input } \\
\text { menu }\end{array}$ & Berhasil \\
\hline $\begin{array}{l}\text { Admin } \\
\text { Memasukkan } \\
\text { data kategori } \\
\text { tempat }\end{array}$ & $\begin{array}{l}\text { Pada modul } \\
\text { admin muncul } \\
\text { halaman input } \\
\text { kategori tempat }\end{array}$ & Berhasil \\
\hline $\begin{array}{l}\text { Admin } \\
\text { memasukkan } \\
\text { data user }\end{array}$ & $\begin{array}{l}\text { Pada modul } \\
\text { admin muncul } \\
\text { halaman input } \\
\text { user }\end{array}$ & Berhasil \\
\hline $\begin{array}{l}\text { Pelanggan } \\
\text { melihat daftar } \\
\text { menu }\end{array}$ & $\begin{array}{l}\text { Pada modul } \\
\text { pelanggan } \\
\text { muncul halaman } \\
\text { daftar menu }\end{array}$ & Berhasil \\
\hline $\begin{array}{l}\text { Pelanggan } \\
\text { melihat daftar } \\
\text { kategori } \\
\text { tempat }\end{array}$ & $\begin{array}{l}\text { Pada modul } \\
\text { pelanggan } \\
\text { muncul halaman } \\
\text { daftar kategori } \\
\text { tempat }\end{array}$ & Berhasil \\
\hline $\begin{array}{l}\text { Pelanggan } \\
\text { melakukan } \\
\text { pemesanan }\end{array}$ & $\begin{array}{lr}\text { Pada modul } \\
\text { pelanggan, } \\
\text { setelah button } \\
\text { "Reserve" } \\
\text { akan diklik } \\
\text { halaman } & \text { tampil } \\
\text { pesanan } & \\
\end{array}$ & Berhasil \\
\hline $\begin{array}{l}\text { Pelanggan } \\
\text { maupun admin } \\
\text { melakukan } \\
\text { pembatalan } \\
\text { pesanan }\end{array}$ & $\begin{array}{l}\text { Pada modul } \\
\text { pelanggan } \\
\text { maupun admin, } \\
\text { pesanan dapat } \\
\text { dibatalkan } \\
\text { dengan memilih } \\
\text { status "Cancel" }\end{array}$ & Berhasil \\
\hline $\begin{array}{l}\text { Pelanggan } \\
\text { maupun admin } \\
\text { mencetak } \\
\text { invoice }\end{array}$ & $\begin{array}{lr}\text { Pada modul } \\
\text { pelanggan } \\
\text { maupun admin, } \\
\text { invoice dapat } \\
\text { dicetak dengan } \\
\text { mengklik button } \\
\text { "Cetak" }\end{array}$ & Berhasil \\
\hline
\end{tabular}

\section{Kesimpulan}

Dari penelitian yang telah dilakukan, maka dapat diperoleh kesimpulan sebagai berikut:

a. Penggunaan aplikasi dapat membantu Restoran 1953 Indonesia dalam hal mempromosikan dan menangani pesanan pelanggan melalui fitur reservasi menu dan reservasi tempat. Kedua fitur ini menyediakan informasi yang lengkap mengenai detail menu dan harga serta tempat dan spesifikasinya.

b. Proses menghitung total pembayaran jadi lebih mudah karena prosesnya dilakukan melalui aplikasi dengan mengkalkulasi seluruh pesanan pelanggan. Hasilnya juga dapat dibuat dalam bentuk cetak sehingga tidak perlu menulis ulang pada daftar tagihan.

\section{Daftar Pustaka}

Defrina, D., \& Lestari, D. P. (2017). Aplikasi Pemesanan Makanan dan Minuman Online Berbasis Mobile Browser pada Restoran Tiga Saudara. Jurnal Ilmiah Informatika dan Komputer Vol. 22 No. 3, 158-170.

Hariyanto, A. (2015). Membuat Aplikasi Computer Based Test dengan PHP MYSQL dan Bootstrap. Yogyakarta: Andi.

Hendini, A. (2013). Perancangan Aplikasi Pemesanan Menu Makanan dan Minuman Berbasis Android. Jurnal Khatulistiwa Informatika Vol. 1 No. 1 .

Indrajani. (2015). Database Design (Case Study All in One). Jakarta: PT Elex Media Komputindo.

Kusnadi, D. R., \& Hasti, N. (2016, Mei 12). Analisis dan Perancangan Aplikasi Reservasi dan Order Menu Berbasis Web pada Restoran Bebek Van Java. Majalah Ilmiah UNIKOM Vol.14 No. 1, pp. 129-140.

Nidhra, S., \& Dondeti, J. (2012). Blackbox and Whitebox Testing Techniques - A Literature Review. International Journal of Embedded Systems and Applications Vol.2, No.2.

Ninemeier, J., \& Hayes, D. (2006). Restaurant Operations Management Priciples and Pratices. New Jersey: Pratince Hall.

Pressman, R. S. (2015). Rekayasa Perangkat Lunak : Pendekatan Praktisi Buku 1. Yogyakarta: Andi.

Rosa, A., \& Shalahuddin, M. (2013). Rekayasa Perangkat Lunak Terstruktur dan Berorientasi Objek. Bandung: Informatika.

Shi, M. (2010). Software Functional Testing from the Perspective of Business Practice. Computer and Information Science, 49-52. 